\title{
Matrix metalloproteinase-mediation of tumor targeting human recombinant tumor necrosis factor- $\alpha$ fusion protein
}

\author{
HUI REN ${ }^{1}$, XIN SHAO $^{1}$, LIANG ZENG ${ }^{1}$, FA WANG $^{1}$, DI-NAN HUANG ${ }^{2}$ and GAN HOU ${ }^{2}$ \\ ${ }^{1}$ Department of Basic Medicine, Guangdong Medical College, Zhanjiang, Guangdong 524023; \\ ${ }^{2}$ Department of Clinical Biochemistry, Guangdong Medical College, Dongguan, Guangdong 523808, P.R. China
}

Received July 14, 2014; Accepted March 20, 2015

DOI: $10.3892 / \mathrm{mmr} .2015 .3639$

\begin{abstract}
The aim of the present study was to use genetic engineering in order to establish an efficient tumor necrosis factor (TNF)- $\alpha$ fusion protein with low toxicity, which may be used to target tumors. Four types of matrix metalloproteinase (MMP)-mediated tumor targeting human recombinant TNF- $\alpha$ $($ rhTNF- $\alpha$ ) fusion protein vectors were constructed. These were subsequently introduced into Escherichia coli. rhTNF- $\alpha$ fusion protein with a glutathione S-transferase (GST)-tag was purified using GST resin affinity chromatography, and GST-tags were digested using factor Xa. The cytotoxic effects of the fusion protein on L929 cells were determined using MTT assays. At a concentration of $1 \mathrm{pM}$, the GST-tagged fusion protein exerted no cytotoxic effects on the cells, compared with the negative control cells $(\mathrm{P}=0.975>0.05)$. However, at a concentration of $1000 \mathrm{pM}$, the deblocking fusion protein exerted greater cytotoxic effects on L929 cells, compared with positive control cells $(\mathrm{P}<0.05)$. Treatment with the fusion protein also induced cell apoptosis in the nasopharyngeal cancer cell line, CNE-2Z, which secretes high levels of MMP-1. In conclusion, the results of the present study suggested that MMP-mediated rhTNF- $\alpha$ fusion protein induces CNE-2Z cells apoptosis. rhTNF- $\alpha$ exhibits high efficacy and tumor cell targeting capability, with low toxicity effects on healthy cells.
\end{abstract}

\section{Introduction}

Tumor necrosis factor- $\alpha$ (TNF- $\alpha)$ is a pleiotropic factor, which exhibits antitumor effects, alters endothelial barrier function, reduces tumor interstitial pressure and mediates immune responses (1). TNF- $\alpha$ is associated with a number of cell signalling events, is associated with cell necrosis

Correspondence to: Professor Gan Hou, Department of Clinical Biochemistry, Guangdong Medical College, 1 Xingcheng Road, Dongguan, Guangdong 523808, P.R. China

E-mail: 414786515@qq.com

Key words: human recombinant tumor necrosis factor- $\alpha$, glutathione S-transferase-tag, matrix metalloproteinase, fusion protein, methyl tetrazolium, apoptosis and apoptosis, and is important for resistance to infection and cancer $(2,3)$. However, due to its potential side effects, including cytotoxicity to healthy cells as well as cancer cells, for patients with cancer, it is not seen as a viable antitumor therapy, and its use is limited to locoregional treatments (4-7).

Matrix metalloproteinases (MMPs) are a class of endogenous zinc-dependent proteolytic enzymes, which are important for a number of biological processes (8). MMPs are also involved in cancer cell invasion and dissemination (9). MMPs are produced by connective tissue cells, endothelial cells, macrophages, lymphocytes, thymocytes and tumor cells. Tumor cells are hypothesized to utilize the extracellular matrix or the basal lamina degrading capability of these enzymes in order to metastasize to distant sites. High expression of MMP-1,-2,-7,-9 and -13 in patients with cancer is associated with a poor prognosis. MMP-12 expression has been shown to increase angiostatin and decrease vascular endothelial growth factor expression, the balance of which controls angiogenesis of tumor cells $(10,11)$. Therefore, MMP activity may be involved in a number of pathological processes $(12,13)$.

The present study aimed to establish a recombinant human TNF- $\alpha$ (rhTNF- $\alpha$ ) plasmid and to investigate its potential as a targeted tumor therapy. The pET-42a-c(+) vector was selected as an expression vector. MMP sequences and a section of the foldon domain sequence of the T4 bacteriophage fibfitin were inserted into the receptor binding site in the N-terminal region of mutant hTNF- $\alpha$. The foldon domain inhibits the binding of rhTNF- $\alpha$ with TNF receptors and thus, suppress its bioactivity (14). MMPs present in the tumor cells hydrolyze fusion proteins, thereby exposing the receptor binding sites of hTNF- $\alpha$ and consequently inducing tumor cell apoptosis through the action of rhTNF- $\alpha$ on its receptor.

\section{Materials and methods}

Vector, drugs and reagents. The pET-32a-collagen MMP-hTNF- $\alpha$ plasmid was constructed and stored at $-70^{\circ} \mathrm{C}$ with $20 \%$ glycerol. The following materials were obtained from EMD Millipore, Billerica, MA, USA: PET-42a-c(+) vector, factor Xa, BugBuster Protein Extraction Reagent kits and BugBuster GST-Bind Purification kits. BamHI, SpeI, SacI and T4 DNA ligase were obtained from Takara Biotechnology Co., Ltd. (Dalian, China). Isopropyl- $\beta$-D-thiogalactoside (IPTG) was obtained from Sheng Gong Bioscience 
Table I. Primer sequences used in human recombinant tumor necrosis factor- $\alpha$.

\begin{tabular}{lll}
\hline Gene & \multicolumn{1}{c}{ Forward primer $\left(5^{\prime}-3^{\prime}\right)$} & \multicolumn{1}{c}{ Reverse primer (5'-3') } \\
\hline MMP-1 & GCGGATCCCCACTGGCACTGTGGGCACGT & GCGAGCTCTCCTCACAGGGCAATGATCCC \\
& AGTGACAAGCCTGTAGCCCATG & AAAG \\
MMP-2 & GCGGATCCCCACTGGGTCTGTGGGCACGT & GCGAGCTCTCCTCACAGGGCAATGATCCC \\
& AGTGACAAGCCTGTAGCCCATG & AAAG \\
MMP-8 & GCGGATCCCCACTGGCATATTGGGCACGT & GCGAGCTCTCCTCACAGGGCAATGATCCC \\
& AGTGACAAGCCTGTAGCCCATG & AAAG \\
MMP-9 & GCGGATCCCCACTGGGTATGTGGAGCCGT & GCGAGCTCTCCTCACAGGGCAATGATCCC \\
& AGTGACAAGCCTGTAGCCCATG & AAAG \\
\hline
\end{tabular}

Technology Limited Company (Qingdao, China). An MTT kit was purchased from Sigma-Aldrich (St. Louis, MO, USA). The Hoechst Staining kit was purchased from Beyotime Institute of Biotechnology (Haimen, China). Anhydrous ethanol, isopropyl alcohol, hydroxymethanol aminomethane, boric acid, glycerol and ethylene diamine tetraacetic acid were purchased from Fuyuhuagong (Tianjin, China).

Primary instruments. Vertical electrophoresis and electrophoresis apparatus were purchased from Bio-Rad Laboratories (Hercules, CA, USA). A Thermo Scientific Varioskan Flash was purchased from Thermo Fisher Scientific (Waltham, MA, USA). A DK-98-II thermostatic water tank was purchased from Tianjin City Taisite Instrument Co., Ltd. (Tianjing, China). A microscope and relevant software (TE2000-E; Nikon Corporation, Tokyo, Japan) were provided by the Guangdong Medical College (Guangdong, China).

Recombinant plasmid construction. The plasmid pET-42a(+) foldon-MMP-hTNF- $\alpha$ was constructed by cloning the following sequences into the pET-42a(+) vector: Foldon sequence, MMP distinguishing sequence and wild hTNF- $\alpha$ sequence (with 8 amino acids deleted from the $\mathrm{N}$-terminal). The plasmid pET-42a was used as the template for gene splicing using overlap extension polymerase chain reaction (PCR). The following primer was used: Forward: 5'-CGGGATCCTAGGAAGGTGG ACAGCAAGACCCATTCACCATCTTTTCGTACGTAGCC CTGGCCATCTCGTGGTGCTTCTGGAATATACCCGGAC CCGCGTCCCTCAATACCG-3' (italics, BamHI endonuclease sites; underlined, a reverse foldon nucleotide sequence that reversely complements to $16 \mathrm{bp}$ ). A pair of amplification primers was also used. The forward primer (5'-CGGGATCCTAGGAAGGTG-3') included the 5 ' terminal $18 \mathrm{bp}$ of the extension primer, which included the restriction enzyme sites of $B a m \mathrm{HI}$, and the reverse (5'-TTCAACTAGTGGTTCTGG-3') included restriction enzyme sites of SpeI. The PCR conditions were as follows: Denaturation at $98^{\circ} \mathrm{C}$ for $10 \mathrm{sec}$, annealing at $55^{\circ} \mathrm{C}$ for $15 \mathrm{sec}$ and extension at $72^{\circ} \mathrm{C}$ for $20 \mathrm{sec}$, for 30 cycles. Subsequently, the pET-42a plasmid and PCR products containing the foldon sequence were digested using SpeI and BamHI double enzymes, and connected using T4 DNA ligase. The recovered PCR product was directionally cloned into the recovered $\mathrm{pET}-42 \mathrm{a}(+)$ plasmid. Four types of pET-32a-collagen MMP-hTNF- $\alpha$ plasmids used in a previous study (15) were used as templates for
PCR in the present study, in order to obtain four fragments: MMP-1-hTNF- $\alpha$, MMP-2-hTNF- $\alpha$, MMP-8-hTNF- $\alpha$ and MMP-9-hTNF- $\alpha$. The four plasmids shared a common reverse primer, which included the restriction enzyme sites of SacI (GAGCTC), and is shown, together with the forward primers, in Table I. PCR reaction conditions for the double enzyme SacI and BamHI digestion, and for the DNA connection were the same as those already described. Positive colonies were screened using kanamycin (Tiangen Biotech Co., Ltd., Beijing, China), and identification of recombinants and PCR products was confirmed using agarose electrophoresis and chain termination method using an ABI PRISM 310 (Applied Biosystems, Foster City, CA, USA). to analyze DNA sequences. The recombinant plasmid construction process used in the present study is summarized in Fig. 1.

Expression and purification of the fusion protein. Four types of rhTNF- $\alpha$ fusion protein plasmids were inserted into Rosetta 2 (DE3) Escherichia coli (Novagen, Madison, WI, USA) and selected using kanamycin and chloromycetin (Tiangen Biotech Co., Ltd.) at appropriate concentrations, in order to obtain monoclones. Monoclones were added to $4 \mathrm{ml}$ fresh medium LB and the $\mathrm{A}_{600}$ was measured by UV 2100 spectrophotometry (Unico, Shanghai, China). The $A_{600}$ of fresh medium LB was set as 0 , and when the culture reached 0.6, as compared to fresh LB, IPTG was added to the mixture to obtain a final concentration of $0.8 \mathrm{mM}$. Fusion proteins were incubated at $20^{\circ} \mathrm{C}$ for $12 \mathrm{~h}$, centrifuged at $12,000 \mathrm{x}$ g for $1 \mathrm{~min}$ and extracted according to the manufacturer's instructions (BugBuster Protein Extraction Reagent kit; EMD Millipore) and then purified using BugBuster GST-Bind Purification kit (EMD Millipore). Following affinity chromatography, proteins were collected into $1.5 \mathrm{ml}$ tubes, and concentration was determined using the bicinchoninic acid method (BCA; Thermo Fisher Scientific). Bovine serum albumin (BSA; Thermo Fisher Scientific) was used as a standard, and concentration determination was based on the standard curve of BSA. Diluted thrombin (EMD Millipore) was added to the GST affinity chromatography column and incubated for $16 \mathrm{~h}$ at $20^{\circ} \mathrm{C}$. The sepharose chromatography medium was washed three times with $1 \mathrm{X}$ elution buffer (50 mM Tris-HCl, $\mathrm{pH} 8.0$ ). The fusion protein was removed from GST using factor $\mathrm{Xa}$ (EMD Millipore) and the target protein was obtained from the collected elution. Protein concentration was determined using a BCA method. An uncleaved fusion protein was used 

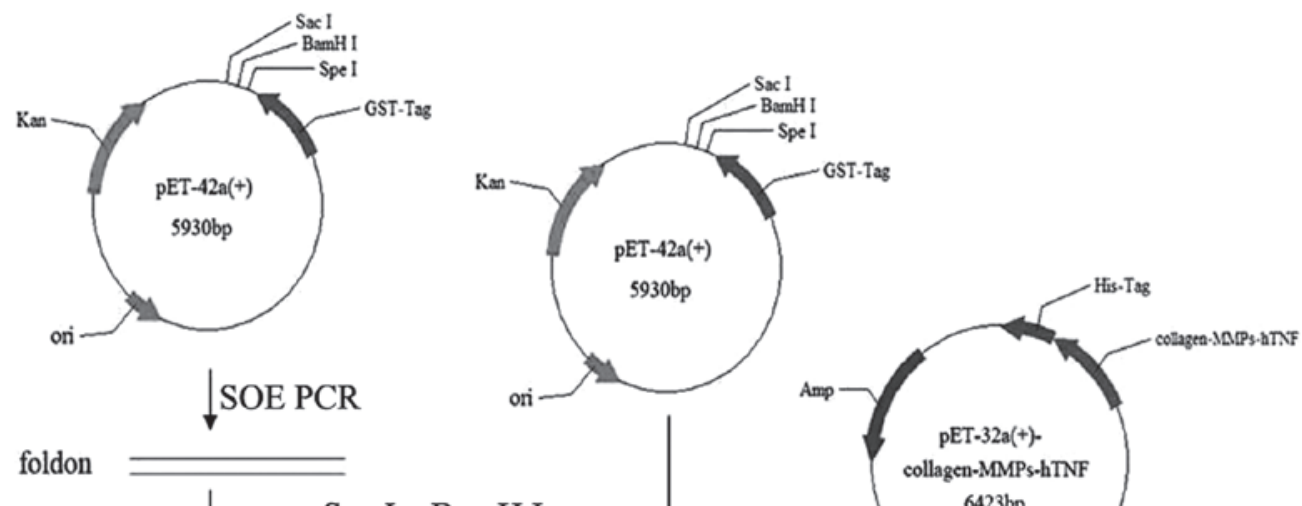

Spe I、BamH I

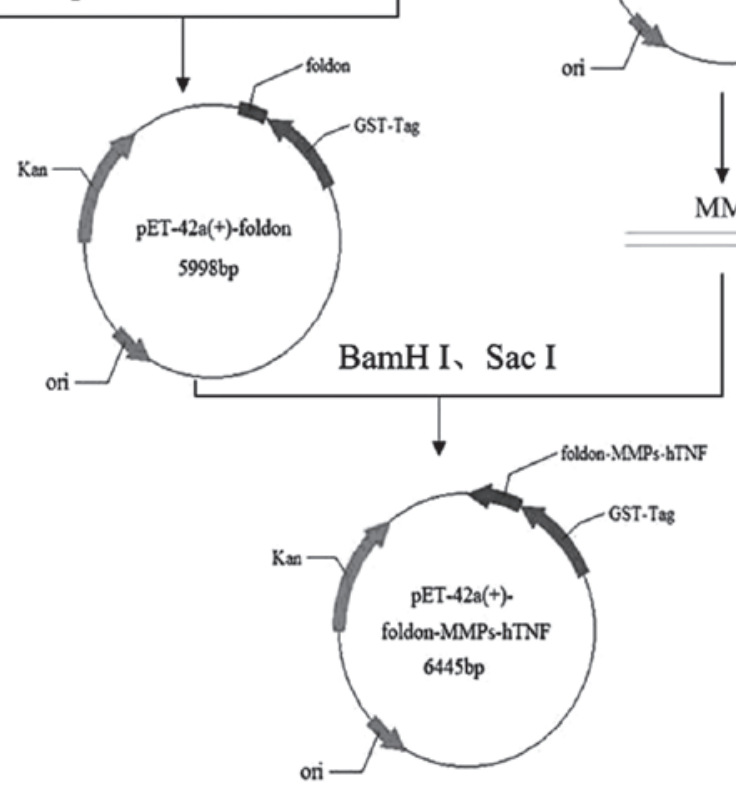

Figure 1. Vector construction of GST-foldon-MMPs-rhTNF- $\alpha$. The pET-42a with the foldon signal peptide was obtained using SOE PCR. The MMP gene was digested with BamHI and SacI, and ligated with T4 ligase and eukaryotic expression vector pET-42a-foldon, which was digested using the same enzymes. rhTNF- $\alpha$, human recombinant tumor necrosis factor- $\alpha$; MMP, matrix metalloproteinase; SOE PCR, splicing by overlap extension polymerase chain reaction; GST, glutathione S-transferase; Kan, kanamycin; ori, origin of replication; His-tag, Histidine-tag; Amp, ampicillin.

as a control. Fusion proteins were further analyzed using $12 \%$ SDS-PAGE. BandScan 5.0 (Bio-Rad Laboratories) software was used to calculate the gray values of the protein bands in the gels, and analyze the results.

Identification of the structure of rhTNF- $\alpha$ fusion protein. A number of studies have shown that the trimeric form of TNF- $\alpha$ is required in order to facilitate its biological activity $(16,17)$. TNF- $\alpha$ consists of high levels of $\beta$-sheets but low levels of $\alpha$-helix. In its active form, the fusion protein foldon-MMPs-hTNF- $\alpha$ is a homotrimer. The N-terminal of foldon may also form trimers independently, promoting the formation of fusion protein trimer and blocking the hTNF- $\alpha$ receptor site. In order to confirm the secondary structure of rhTNF- $\alpha$, the protein tripolymer was analyzed, using polyacrylamide gel electrophoresis.

Effects of MMPs on TNF- $\alpha$ activity. The deblocking effect of MMPs 1,2,8 and 9 on rhTNF- $\alpha$, and the subsequent facilitation of fusion protein activity and tumor specificity, was investigated. 4-aminophenylmercuric acetate is involved in the activation of MMP proenzymes. 4-aminophenylmercuric acetate and
MMP proenzyme (Novagen) were mixed at a ratio of 10:1 and incubated for $45 \mathrm{~min}$ at $37^{\circ} \mathrm{C}$. Subsequently, the mixtures were prepared, with a ratio of MMP to protein of 1:20 ( $\mu \mathrm{l}: \mu \mathrm{g})$. They were then incubated with Tris- $\mathrm{HCl}$ (500-mM; $\mathrm{pH} 8.0$ ) at $37^{\circ} \mathrm{C}$ for $6 \mathrm{~h}$. The substrate sequences of MMPs (MMP1, MMP2, MMP8, MMP9) may be digested by corresponding active MMPs. rhTNF- $\alpha$ products were identified using $12 \%$ SDS-PAGE.

Foldon-MMP-1-hTNF- $\alpha$ fusion protein activity. The bioactivity of purified rhTNF- $\alpha$ was analyzed in L929 cells using an MTT assay. L929 cells were purchased from the Type Culture Collection of the Chinese Academy of Sciences (Shanghai, China). L929 cells are commonly used to study the cytotoxicity of TNF- $\alpha$, as TNF- $\alpha$ is not expressed in these cells. The cells were cultured in RPMI-1640, supplemented with $10 \%$ fetal bovine serum and penicillin-streptomycin (100X; Beyotime Institute of Biotechnology). The exponentially growing cells were digested using $0.25 \%$ trypsin solution (Life Technologies, Carlsbad, CA, USA) and the suspended cells were adjusted to $2 \times 10^{5}$ cell $/ \mathrm{ml}$. Using an RPMI-1640 culture, containing $1 \mu \mathrm{g} / \mathrm{ml}$ of actinomycin D, 

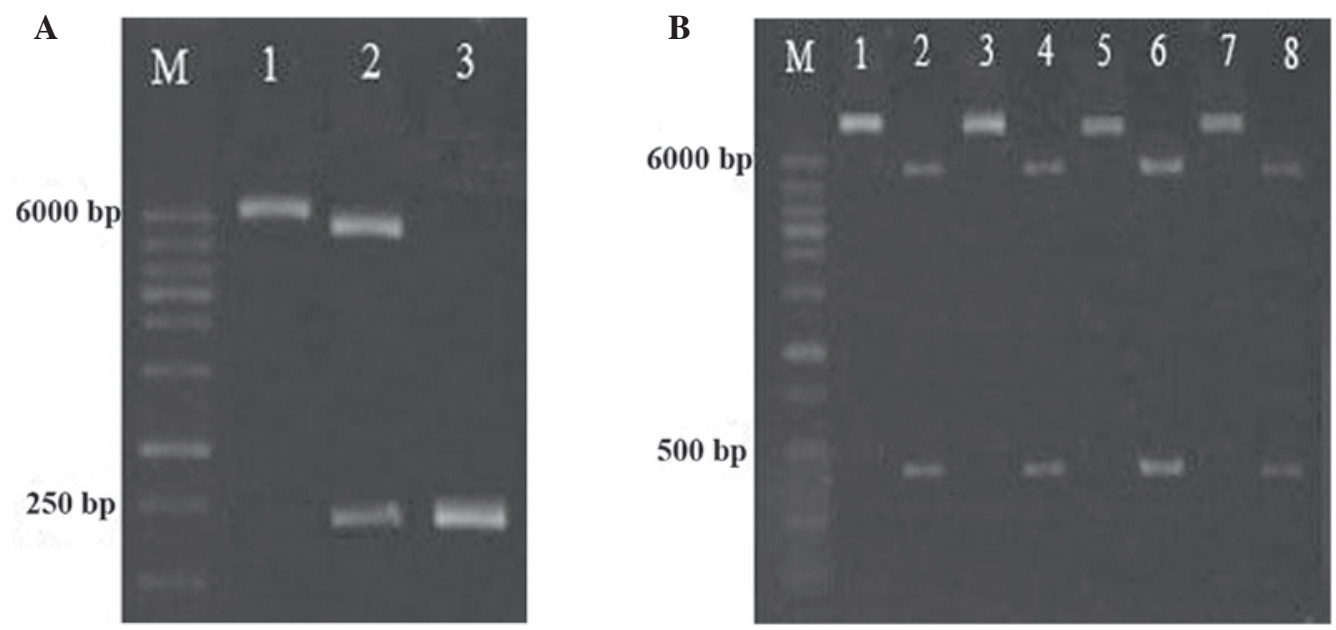

Figure 2. Identification of GST-foldon-MMPs-hrTNF- $\alpha$ plasmid. (A) Electrophoresis of SpeI and BamHI digested products and PCR products. Lane 1, pET-42a(+)-foldon (5,998 bp); lane 2, endonuclease-digested products (5,950 and 249 bp); lane 3, PCR product (261 bp). (B) Enzyme-digested products and PCR product of recombinant plasmid. Lanes 1,3,5 and 7 represent recombinant plasmids $(5,959 \mathrm{bp})$, and lanes $2,4,6$ and 8 represent enzyme-digested products (484 bp). M, molecular weight marker (100-6,000 bp); GST, glutathione S-transferase; rhTNF- $\alpha$, human recombinant tumor necrosis factor- $\alpha$; PCR, polymerase chain reaction.
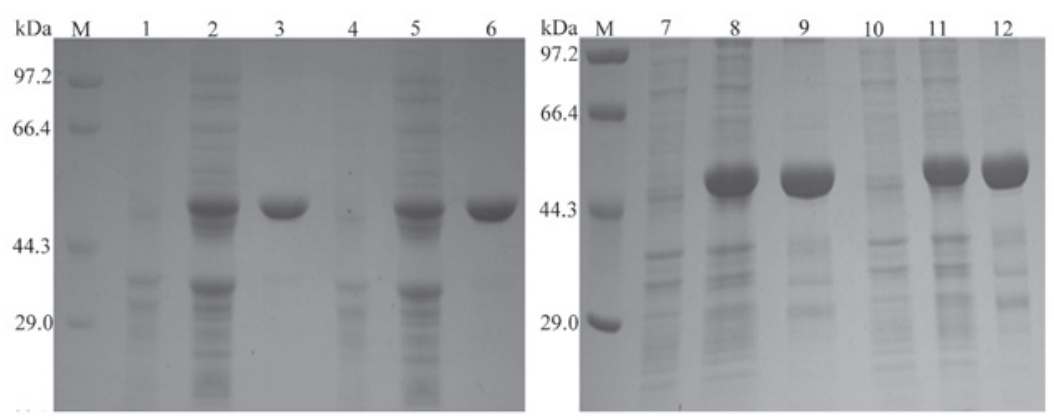

Figure 3. Expression and purification of fusion protein. Lanes 1, 4, 7 and 10 represent noninduced total bacterial proteins; lanes 2, 5, 8 and 11 represent total protein following IPTG induction; and lanes 3, 6, 9 and 12 represent rhTNF- $\alpha$ fusion proteins. M, molecular weight marker; rhTNF- $\alpha$, human recombinant tumor necrosis factor- $\alpha$; IPTG, isopropyl- $\beta$-D-thiogalactoside.

cells $(100 \mu \mathrm{l} /$ well) were cultured in a 96 -well culture plate and incubated at $37^{\circ} \mathrm{C}$ with $5 \% \mathrm{CO}_{2}$ for $24 \mathrm{~h}$. The following concentrations of fusion protein were used: $1,10,100$ and $1000 \mathrm{pM}$. A negative control group was treated with physiological saline only. Experiments were repeated three times. Following an incubation period of $24 \mathrm{~h}$ at $37^{\circ} \mathrm{C}$ with $5 \%$ $\mathrm{CO}_{2}, 10 \mu \mathrm{l}$ MTT $(5 \mathrm{mg} / \mathrm{ml})$ was added to the wells. The plate was further incubated at $37^{\circ} \mathrm{C}$ for $4 \mathrm{~h}$. Supernatants were subsequently aspirated and crystals were dissolved by adding dimethyl sulfoxide $(200 \mu \mathrm{l})$ to the wells and incubating for $30 \mathrm{~min}$ at $37^{\circ} \mathrm{C}$. Absorbance at $570 \mathrm{~nm}$ was measured using a Varioskan Flash 5250030 enzyme-labeled meter (Thermo Fisher Scientific), following agitation. Cell activity was then calculated and the dilution at which $50 \%$ of cell were inactive, was recorded as the active unit (U). The value of the median lethal dose was calculated using SPSS 19.0 (SPSS, Inc., Chicago, IL, USA). Cultures were incubated for $24 \mathrm{~h}$, subsequently cell morphology was observed using a fluorescence microscope (TE2000-E; Nikon Corporation).

Hoechst 33258 staining of apoptotic cells. Asssessment of apoptosis was conducted according to the methods described in a previous study (18). In the current study, CNE-2Z poorly differentiated nasopharyngeal carcinoma cells (Department of Pathology, Affiliated Hospital of Guangdong Medical College) were used as target cells. They were digested using $0.25 \%$ trypsin solution and the suspended cell concentration was adjusted to $2.5 \times 10^{5} \mathrm{cell} / \mathrm{ml}$. The four treatment groups (identical to those in the MMT assay), cultured to 50-80 confluence\%, were cultured with the rhTNF- $\alpha$ for $24 \mathrm{~h}$. Results were observed using fluorescence microscopy.

Statistical analysis. Statistical analysis was conducted using analysis of variance with SPSS 19.0. Experiments were performed three times. Data are presented as the mean \pm standard deviation. $\mathrm{P}<0.05$ was considered to indicate a statistically significant difference.

\section{Results}

Recombinant plasmid construction. As shown in Fig. 2A, two bands were observed following double SpeI and BamHI digestion. Sequencing results suggested that the foldon gene was successfully inserted into the plasmid vector pET-42a(+), and two bands were observed at 500 and $6000 \mathrm{bp}$, following digestion with SacI and BamHI (Fig. 2B). The results of base 
Table II. Results of MTT assay showing cytotoxic effects of different proteins on L929 cells.

\begin{tabular}{|c|c|c|c|c|c|}
\hline Group & $\begin{array}{c}\text { Concentration }^{\mathrm{a}} \\
(\mathrm{pM})\end{array}$ & $\mathrm{A} 570^{\mathrm{a}}$ & $\begin{array}{l}\text { Cytotoxicity } \\
(\%)^{\mathrm{b}}\end{array}$ & LD50 (pM) & $\begin{array}{c}\text { Specific } \\
\text { radioactivity }^{\mathrm{c}}\end{array}$ \\
\hline \multirow[t]{2}{*}{ Negative control } & 0 & $0.544 \pm 0.04$ & & & \\
\hline & 1 & $0.435 \pm 0.02$ & 20.04 & & \\
\hline \multirow[t]{3}{*}{ hTNF- $\alpha$} & 10 & $0.314 \pm 0.012$ & 42.28 & & \\
\hline & 100 & $0.169 \pm 0.013$ & 68.93 & & \\
\hline & 1000 & $0.126 \pm 0.011$ & 76.84 & 24.95 & 2.35 \\
\hline \multirow[t]{4}{*}{ GST-foldon-MMP1-rhTNF- $\alpha$} & 1 & $0.543 \pm 0.017^{*}$ & 0.18 & & \\
\hline & 10 & $0.401 \pm 0.019$ & 26.28 & & \\
\hline & 100 & $0.338 \pm 0.023$ & 37.87 & & \\
\hline & 1000 & $0.238 \pm 0.024$ & 56.25 & 401.79 & 0.146 \\
\hline \multirow[t]{4}{*}{ rhTNF- $\alpha$} & 1 & $0.334 \pm 0.013$ & 38.60 & & \\
\hline & 10 & $0.310 \pm 0.006$ & 43.01 & & \\
\hline & 100 & $0.157 \pm 0.009$ & 71.14 & & \\
\hline & 1000 & $0.103 \pm 0.008^{* *}$ & 81.07 & 9.045 & 6.48 \\
\hline
\end{tabular}

${ }^{a}$ Values are presented as the mean \pm standard deviation $(\mathrm{n}=3)$; ${ }^{\mathrm{P}} \mathrm{P}$-values were calculated using the single factor analysis of variance; ${ }^{\mathrm{c}} \mathrm{U} / \mathrm{mg}, 1 \mathrm{x} 10^{7}$. Negative control was treated with physiological saline. " $\mathrm{P}=0.939>0.05$, compared with the negative control cells; ${ }^{* *} \mathrm{P}-0.139>0.05$, compared with the hTNF- $\alpha$ group cells. rhTNF- $\alpha$, human recombinant tumor necrosis factor- $\alpha$; GST, glutathione S-transferase; LD50, median lethal dose.

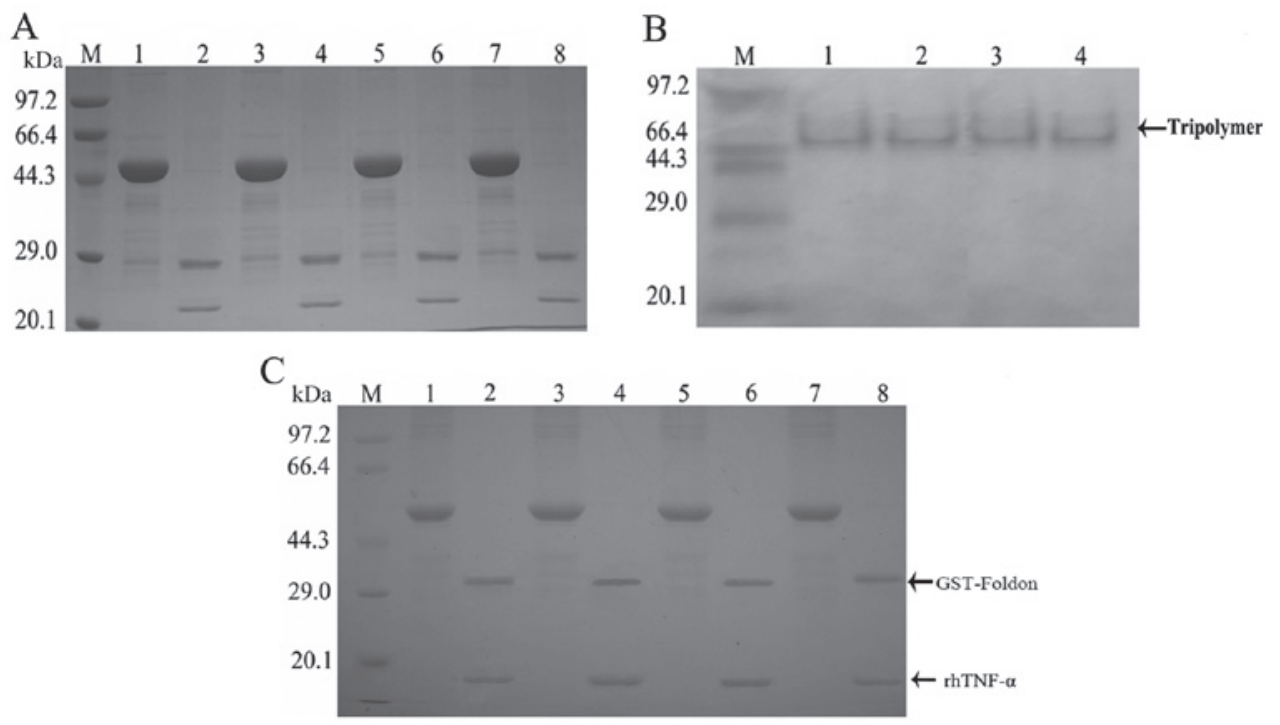

Figure 4. SDS-PAGE analysis of purified fusion proteins. (A) Factor Xa was used to remove GST from the fusion protein (49 KDa), which was cleaved into two parts: GST (28 KDa) and foldon-MMPs-TNF- $\alpha$ (21 KDa). Lanes 1, 3, 5 and 7 represent total protein purified using GST resin; lanes 2, 4, 6, and 8 represent the digestion products using factor Xa. (B) Gel electrophoresis analysis of fusion protein tripolymer. (C) MMP digestion products. Fusion protein (49 KDa) was cleaved into two parts: GST-foldon (32 KDa) and rhTNF- $\alpha$ (17 KDa). GST, glutathione S-transferase; rhTNF- $\alpha$, human recombinant tumor necrosis factor- $\alpha$.

sequencing suggested that no base mutation had occurred in the two fragments.

Expression and purification of fusion proteins. SDS-PAGE analysis suggested that a protein band $>44.3 \mathrm{kDa}$ was amplified, which represents a molecular weight near to the expected molecular size of $49 \mathrm{kDa}$. This was in contrast to the negative control sample, consisting of total bacterial proteins without the ITPG inducer. According to BandScan software analysis, the proportions of the four types of purified fusion proteins in total protein levels were 100, 100, 80.6 and 82.1\%, respectively (Fig. 3).
Factor Xa hydrolysis, trimer formation and MMP influence on the fusion proteins. As predicted the molecular weight of the protein of interest was $\sim 21 \mathrm{kDa}$ and that of the vector label was $\sim 28 \mathrm{kDa}$; there were two protein bands between 20.1 and $29.0 \mathrm{kDa}$ present following digestion with factor XA (Fig. 4A). The molecular weight of the trimeric forms of fusion protein was $\sim 63 \mathrm{kDa}$, and bands appeared at $\sim 66.4 \mathrm{kDa}$, following gel electrophoresis (Fig. 4B). Two bands at 14.3-20.1 and 29.0-44.3 kDa, were observed in rhTNF- $\alpha$ samples, in the presence of restriction enzymes. By contrast these bands were not observed in rhTNF- $\alpha$ samples without restriction enzymes. 


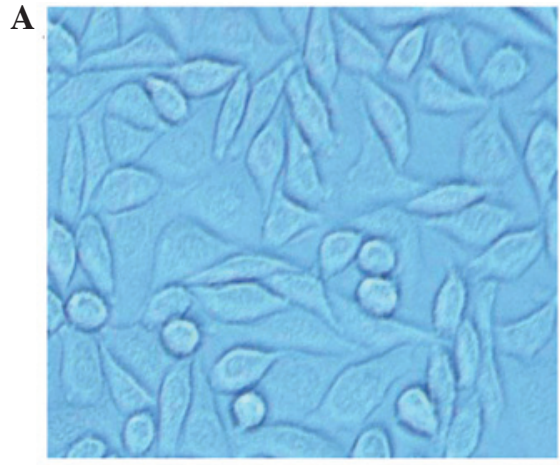

C

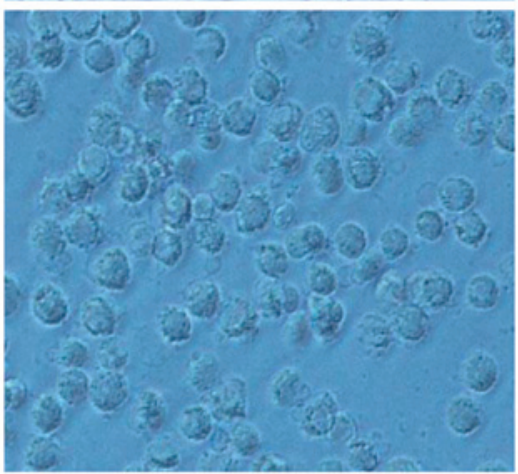

B

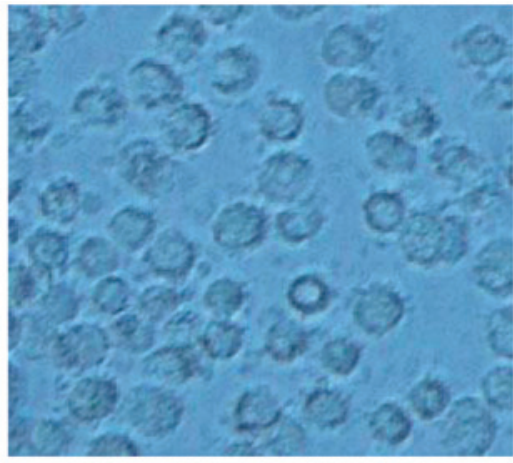

D

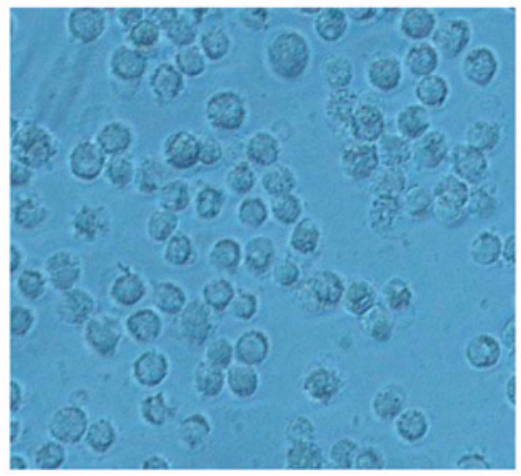

Figure 5. Treatment of L929 cells with fusion protein for $24 \mathrm{~h}$. (A) Negative control (L929 cells treated with physiological saline). (B) Treatment with hTNF- $\alpha$. No cell connections were observed and there were a number of nuclear membrane ruptures. Cell membranes were dissolved. (C) GST-foldon-MMP1-rhTNF- $\alpha$ and (D) rhTNF- $\alpha$ groups. Magnification, x100. GST, glutathione S-transferase; hrTNF- $\alpha$, human recombinant tumor necrosis factor- $\alpha$; MMP, matrix metalloproteinase.

A

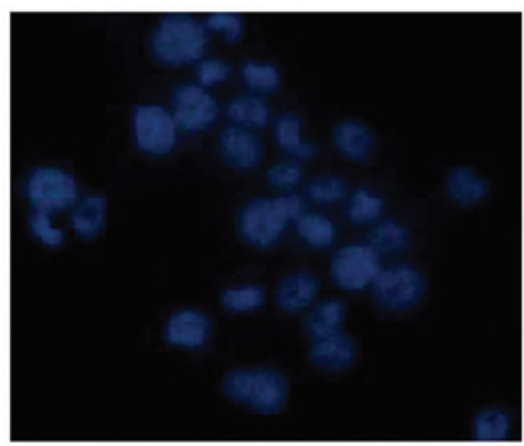

C

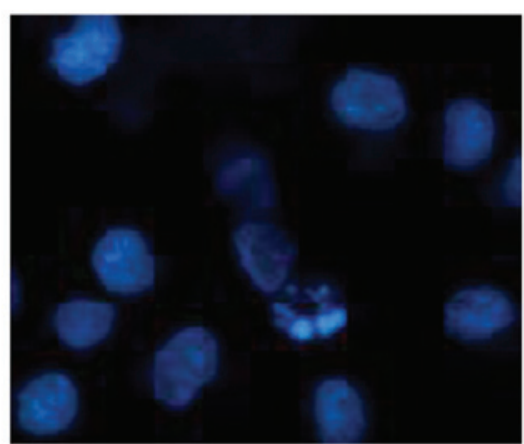

B

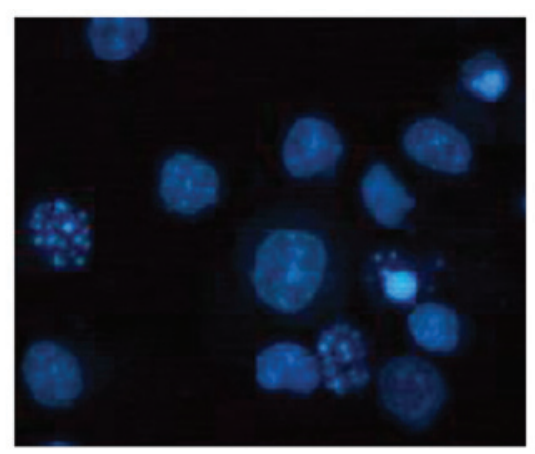

$\mathbf{D}$

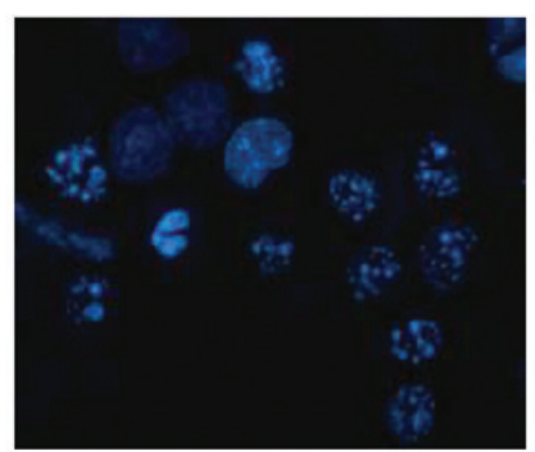

Figure 6. Hoechst staining of CNE-2Z cells. Living cells appear blue, while apoptotic cells appear bright blue with a lobulated nucleus. (A) Negative control (CNE-2Z cells treated with physiological saline). (B) hTNF- $\alpha$, (C) GST-foldon-MMP1-rhTNF- $\alpha$ and (D) rhTNF- $\alpha$. Magnification, x100. GST, glutathione S-transferase; hrTNF- $\alpha$, human recombinant tumor necrosis factor- $\alpha$.

Furthermore, since the fusion protein comprises the substrate sequence of MMPs, after MMP digestion the fusion protein (49 kDa) was cleaved into two parts: GST-foldon (32 kDa) and rhTNF- $\alpha$ (17 kDa). Therefore, MMP appeared to successfully deblock the fusion protein (Fig. 4C).
Cytotoxicity assay of rhTNF- $\alpha$ fusion protein. Compared with the control, the inhibition rate of MMP-1-hTNF- $\alpha$ was $81.07 \%$ in the $1000 \mathrm{pM}$ group $(\mathrm{P}<0.05)$ and the specific activity of the purified MMP-1-hTNF- $\alpha$ was $\sim 6.48 \times 10^{7} \mathrm{U} / \mathrm{mg}$. By contrast, the GST-foldon-MMP-1-hTNF- $\alpha$ exhibited no 
significant effects on L929 cells (Table II). Following treatment for $24 \mathrm{~h}$ in the negative control cells, normal cell arrangement was observed, cells were fusiform in shape, the refractive index was good and the boundaries of cell membranes were clear. However, the growth inhibition rates of L929 cells were different in the three experimental groups (Fig. 5).

Apoptosis assay. During the terminal phase of cell apoptosis, chromatin typically condenses and becomes marginalized, the nucleus breaks down, the nuclear membrane may be dissolved and apoptotic bodies appear. In the present study, apoptosis was observed in the rhTNF- $\alpha$ positive control cells (Fig. 6). The influence of $\operatorname{rhTNF}-\alpha$ on cell cycle arrest remains to be investigated.

\section{Discussion}

Prodrugs refer to chemical compounds, which are administered in an inactive form and require metabolic processing in order to be converted into an active form (19). In tumor cells there anre numerous types of substances that may be used as prodrug targets, including overexpressed enzymes, peptides, transport proteins and antigens (20). TNF- $\alpha$ recombinant fusion proteins may be constructed using gene engineering technology by combining certain cytokines or targeting peptides. Prodrugs do not exhibit bioactivity until the required catalytic reactions occur in the target tissues. Following MMP hydrolyzation, fusion proteins are converted to cytotoxic drugs, which result in tumor cell apoptosis and, therefore, may be an effective antitumor therapy $(21,22)$.

In the present study, hTNF- $\alpha$ was the active component, while MMPs were used to specifically target tumor tissue and form peptide bonds with tumor cells (23). Folden is able to block the TNF- $\alpha$ receptor binding site, while MMPs hydrolyze the fusion protein and expose the receptor binding site. The integration of MMPs and hTNF- $\alpha$ thus allows the hTNF- $\alpha$ fusion protein to retain targeted antitumor activity, while concomitantly exerting low toxicity on healthy cells. In the present study, four types of hrTNF- $\alpha$ plasmid were established using PCR methods. The bioactive form of hrTNF- $\alpha$ is a non-covalently linked trimer. hrTNF- $\alpha$ monomers consist of two $\beta$-pleated sheets and five antiparallel $\beta$-bundles. Extrinsic $\beta$-pleated sheets are enriched with hydrophilic residues, while the internal $\beta$-bundles are hydrophobic. Combined $\beta$ structures of hrTNF- $\alpha$ form stable hrTNF- $\alpha$ trimers (24). The molecular weight of fusion proteins in their trimeric forms is typically $\sim 63 \mathrm{kDa}$ (15). In the present study, bands were $\sim 66.4 \mathrm{kDa}$ according to gel electrophoresis, which is similar to the known secondary structure of native hrTNF- $\alpha$ (25). This suggests that fusion protein trimers are formed in vitro.

Furthermore, fusion protein yields may be improved using affinity tags, such as GST. Certain affinity tags are capable of promoting fusion protein solubility levels and they may inhibit the incorporation of fusion proteins into insoluble inclusion bodies $(26,27)$. GST is a commonly-used tag with which to express and purify fusion proteins. GST-tags enhance the ability of fusion proteins to be absorbed into affinity matrices, containing covalently-bound GSH. The insertion of a GST tag into the pET-42a(+) vector allowed purification of the extracted fusion proteins using affinity chromatography.
Experiments examining digestion of the fusion protein using MMP, suggested that MMP exerted strong and specific activation effects on the fusion protein.

The present study showed that fusion protein treatment for $24 \mathrm{~h}$ inhibited $\mathrm{L} 929$ cell proliferation in a dose-dependent manner. Theoretically, the rhTNF- $\alpha$ fusion protein should not exhibit the biological activity of hTNF- $\alpha$, nor exert cytotoxic effects on L929 cells. Furthermore, at $\sim 6.48 \times 10^{7} \mathrm{U} / \mathrm{mg}$ MMP-1-hTNF- $\alpha$ induced fusion protein activity. Reduced cytotoxicity was observed following GST-foldon-MMP-1-hTNF- $\alpha$ treatment, compared with rhTNF- $\alpha$ treatment. It was hypothesized that L929 cells may produce low levels of MMPs, which resulted in deblocking of the fusion protein and subsequent biological activity of hTNF- $\alpha$ biological. A prominent clinical feature of nasopharyngeal carcinoma is its ability to invade local tissues and to metastasize (28). In the present study, rhTNF- $\alpha$ was capable of targeting nasopharyngeal carcinoma cells, confirming that the fusion protein activity exhibited antitumor effects in vitro. However, in order to achieve these effects, the required dose of hTNF- $\alpha$ is 10-50 times the that which the human body is able to tolerate. Furthermore, tumor cell lines vary in their levels of sensitivity to TNF- $\alpha$. In certain cells, TNF- $\alpha$ may promote tumor cell proliferation. Therefore, further investigation using different cell lines and dosages is required.

In conclusion, the results of the present study provide novel insights into MMP-mediated rhTNF- $\alpha$ fusion protein activity. The fusion protein exhibited tumor-targeting capabilities and low levels of toxicity in healthy cells. Furthermore, the present study demonstrated that rhTNF- $\alpha$ is a potential therapeutic drug for patients with cancer. The development of clinical applications will facilitate the use of fusion proteins in the treatment of tumors.

\section{Acknowledgements}

The present study was supported by The First Science and Technology Program of Guangdong province (grant no. 2008B030301023) and the Science and Technology Program of Higher Learning Institutions in Dongguan (grant nos. 200910815264 and 2012108102016).

\section{References}

1. Locksley RM, Killeen $\mathrm{N}$ and Lenardo MJ: The TNF and TNF receptor superfamilies: Integrating mammalian biology. Cell 104: 487-501, 2001

2. Idriss HT and Naismith JH: TNF alpha and the TNF receptor superfamily: Structure-function relationship(s). Microsc Res Tech 50: 184-195, 2000.

3. Palladino MA Jr, Patton JS, Figari IS and Shalaby MR: Possible relationships between in vivo antitumour activity and toxicity of tumour necrosis factor-alpha. Ciba Found Symp 131: 21-38, 1987.

4. Asher A, Mulé JJ, Reichert CM, Shiloni E and Rosenberg SA: Studies on the anti-tumor efficacy of systemically administered recombinant tumor necrosis factor against several murine tumors in vivo. J Immunol 138: 963-974, 1987.

5. Rice TW, Wheeler AP, Morris PE, Paz HL, Russell JA, Edens TR and Bernard GR: Safety and efficacy of affinity-purified, anti-tumor necrosis factor-alpha, ovine fab for injection (CytoFab) in severe sepsis. Crit Care Med 34: 2271-2281, 2006.

6. Qiu P, Cui X, Barochia A, Li Y, Natanson C and Eichacker PQ: The evolving experience with therapeutic TNF inhibition in sepsis: Considering the potential influence of risk of death. Expert Opin Investig Drugs 20: 1555-1564, 2011. 
7. Jiang C, Niu J, Li M, Teng Y, Wang H and Zhang Y: Tumor vasculature-targeted recombinant mutated human TNF- $\alpha$ enhanced the antitumor activity of doxorubicin by increasing tumor vessel permeability in mouse xenograft models. PLoS One 9: e87036, 2014.

8. John A and Tuszynski G: The role of matrix metalloproteinases in tumor angiogenesis and tumor metastasis. Pathol Oncol Res 7: $14-23,2001$.

9. Ryzhakova OS and Solov'eva NI: Matrix metalloproteinases (MMP) - MMP-1,-2,-9 and its endogenous activity regulators in transformed by E7 oncogene HPV16 and HPV18 cervical carcinoma cell lines. Biomed Khim 59: 530-540, 2013 (In Russian).

10. Decock J, Thirkettle S, Wagstaff L and Edwards DR: Matrix metalloproteinases: Protective roles in cancer. J Cell Mol Med 15: 1254-1265, 2011.

11. Overall CM and Kleifeld O: Tumour microenvironment - opinion: Validating matrix metalloproteinases as drug targets and anti-targets for cancer therapy. Nat Rev Cancer 6: 227-239, 2006

12. Said AH, Raufman JP and Xie G: The role of matrix metalloproteinases in colorectal cancer. Cancers (Basel) 6: 366-375, 2014.

13. Spinale FG and Villarreal F: Targeting matrix metalloproteinases in heart disease: Lessons from endogenous inhibitors. Biochem Pharmacol 90: 7-15, 2014.

14. Meier S, Güthe S, Kiefhaber T and Grzesiek S: Foldon, the natural trimerization domain of T4 fibritin, dissociates into a monomeric A-state form containing a stable beta-hairpin: Atomic details of trimer dissociation and local beta-hairpin stability from residual dipolar couplings. J Mol Biol 344: 1051-1069, 2004.

15. Zhao Q, Hou G, Huang D and Chen S: Construction and expression of hTNF-alpha fusion protein mediated by MMP1 Sheng Wu Yi Xue Gong Cheng Xue Za Zhi 28: 534-537, 2011 (In Chinese).

16. Soma G, Kitahara N, Tsuji Y, et al: Improve of cytotoxicity of tumor necrosis factor (TNF) by increase in basicity of its N-terminal region. Biochem Biophys Res Commun 148: 629-635, 1987.

17. Baeyens KD, De Bondt HL, Raeymaekers A, Fiers W and De Ranter CJ: The structure of mouse tumour-necrosis factor at 1.4 A resolution: Towards modulation of its selectivity and trimerization. Acta Crsyrallogr D Biol Crystallogr 55: 772-778, 1999.
18. Kasibhatla S, Amarante-Mendes GP, Finucane D, Brunner T, Bossy-Wetzel E and Green DR: Staining of suspension cells with hoechst 33258 to detect apoptosis. CSH Protoc 2006: pii: pdb. prot4492, 2006.

19. Zhang Y, Hong H and Cai W: Tumor-targeted drug delivery with aptamers. Curr Med Chem 18: 4185-4194, 2011.

20. Graf N and Lippard SJ: Redox activation of metal-based prodrugs as a strategy for drug delivery. Adv Drug Deliv Rev 64: 993-1004, 2012.

21. Awad AE, Kandalam V, Chakrabarti S, Wang X, Penninger JM, Davidge ST, Oudit GY and Kassiri Z: Tumor necrosis factor induces matrix metalloproteinases in cardiomyocytes and cardiofibroblasts differentially via superoxide production in a PI3Kgamma-dependent manner. Am J Physiol Cell Physiol 298: C679-C692, 2010.

22. Torbati E, Ghassab RK and Davachi ND: Recombinant HCV core protein and the secretion of associated cytokines (IL-6, TNF- $\alpha$ and IFN- $\gamma$ ) in immunized mice. Pak J Biol Sci 16: 2041-2045, 2013

23. Roy R, Yang J and Moses MA: Matrix metalloproteinases as novel biomarkers and potential therapeutic targets in human cancer. J Clin Oncol 27: 5287-5297, 2009.

24. Douni E, Rinotas V, Makrinou E, et al: A RANKL G278R mutation causing osteopetrosis identifies a functional amino acid essential for trimer assembly in RANKL and TNF. Hum Mol Genet 21: 784-798, 2012.

25. Zhang C, Liu Y, Zhao D, Li X, Yu R and Su Z: Facile purification of Escherichia coli expressed tag-free recombinant human tumor necrosis factor alpha from supernatant. Protein Expr Purif 95: 195-203, 2014.

26. Waugh DS: Making the most of affinity tags. Trends Biotechnol 23: 316-320, 2005.

27. Vinckier NK, Chworos A and Parsons SM: Improved isolation of proteins tagged with glutathione S-transferase. Protein Expr Purif 75: 161-164, 2011

28. Ben Nasr H, Chahed K, Remadi S, Zakhama A and Chouchane L: Expression and clinical significance of latent membrane protein-1, matrix metalloproteinase-1 and Ets-1 transcription factor in tunisian nasopharyngeal carcinoma patients. Arch Med Res 40: 196-203, 2009. 